\title{
Comparison of TOMS retrievals and UVMRP measurements of surface spectral UV radiation in the United States
}

\author{
M. Xu' ${ }^{1}$, X.-Z. Liang ${ }^{1,4}$, W. Gao ${ }^{2}$, and N. Krotkov ${ }^{3}$ \\ ${ }^{1}$ Division of Illinois State Water Survey, Institute of Natural Resource Sustainability, University of Illinois, 2204 Griffith, \\ Champaign, IL 61820, USA \\ ${ }^{2}$ USDA UB-B Monitoring and Research Program, Natural Resource Ecology Laboratory, Colorado State University, Fort \\ Collins, CO 80523-1499, USA \\ ${ }^{3}$ Univeristy of Maryland, Goddard Earth Sciences and Technology Center, Baltimore County, MD 21228, USA \\ ${ }^{4}$ Department of Atmospheric Sciences, University of Illinois, Urbana, IL 61801, USA
}

Received: 20 February 2010 - Published in Atmos. Chem. Phys. Discuss.: 23 April 2010

Revised: 24 August 2010 - Accepted: 3 September 2010 - Published: 16 September 2010

\begin{abstract}
Surface noontime spectral ultraviolet (UV) irradiances during May-September of 2000-2004 from the total ozone mapping spectrometer (TOMS) satellite retrievals are systematically compared with the ground measurements at 27 climatological sites maintained by the USDA UV-B Monitoring and Research Program. The TOMS retrievals are evaluated by two cloud screening methods and local air quality conditions to determine their bias dependencies on spectral bands, cloudiness, aerosol loadings, and air pollution. Under clear-sky conditions, TOMS retrieval biases vary from $-3.4 \%$ (underestimation) to $23.6 \%$ (overestimation). Averaged over all sites, the relative mean biases for $305,311,325$, and $368 \mathrm{~nm}$ are respectively $15.4,7.9,7.6$, and $7.0 \%$ (overestimation). The bias enhancement for $305 \mathrm{~nm}$ by approximately twice that of other bands likely results from absorption by gaseous pollutants $\left(\mathrm{SO}_{2}, \mathrm{O}_{3}\right)$, and aerosols that are not included in the TOMS algorithm. For all bands, strong positive correlations of the TOMS biases are identified with aerosol optical depth, which explains nearly $50 \%$ of the variances of TOMS biases. The more restrictive in-situ cloud screening method reduces the biases by $3.4-3.9 \%$ averaged over all sites. This suggests that the TOMS biases from the in-situ cloud contamination may account for approximately $25 \%$ for $305 \mathrm{~nm}$ and $50 \%$ for other bands of the total bias. The correlation coefficients between total-sky and clear-sky biases across 27 sites are $0.92,0.89,0.83$, and 0.78 for 305 , 311,325 , and $368 \mathrm{~nm}$, respectively. The results show that the spatial characteristics of the TOMS retrieval biases are systematic, representative of both clear and total-sky conditions.
\end{abstract}

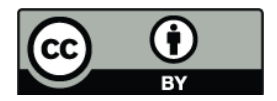

Correspondence to: X.-Z. Liang (xliang@illinois.edu)

\section{Introduction}

Increasing surface ultraviolet (UV) radiation due to stratospheric ozone depletion by anthropogenic emissions has been a topic of growing interest as it is harmful to humans, livestock, agricultural crops, and forest ecosystems (Zerefos et al., 1995; Norval et al., 2006; Caldwell et al., 2006; Bais et al., 2007; Denman et al., 2007). In urban areas where population is dense, large aerosol loadings and heavy air pollutions can cause certain attenuations, but UV amounts are still high and harmful for long exposure under the sun, especially in summer. Chances of sun burn and skin cancer from UV radiation increase as people are spending more time in rural scenic spots and beaches for vacations. In addition, UV radiation is an active agent for photochemical reactions to form smog and particular matters, which are also harmful to public health. Therefore, it is necessary to establish a monitoring network along with a forecast system to provide high-quality UV information for impact studies.

In response to the surface UV increase, the United States has established several ground-based UV monitoring networks since the early 1990s (Scotto et al., 1988; Bigelow et al., 1998; Sabburg et al., 2002). The largest network is maintained by the UV-B Monitoring and Research Program (UVMRP), started by the US Department of Agriculture (USDA) in 1992. It currently includes 36 climatological sites across the US, predominately located in agricultural or rural areas and a few in urban and non-agricultural lands (Bigelow et al., 1998). All sites are instrumented with the same multi-filter rotating shadowband radiometer (MFRSR) that measures spectral UV global (direct sun plus diffuse sky) and diffuse irradiances in seven wavelength bands centered at $300,305,311,317,325,332$,

Published by Copernicus Publications on behalf of the European Geosciences Union. 
and $368 \mathrm{~nm}$ with nominal 2-nm full-width-at-half-maximum (FWHM) spectral response functions (SRFs) annually calibrated by the NOAA Central Ultraviolet Calibration Facility (CUCF) (Bigelow et al., 1998; Slusser et al., 2002).

Meanwhile, satellite retrievals have been developed to estimate surface UV irradiance distribution over the globe from measured backscattered UV irradiance, accounting for the effects of stratospheric ozone, clouds, aerosols, surface albedo, and altitude (Eck et al., 1995; Krotkov et al., 1998, 2002; Herman et al., 1999). In particular, the total ozone mapping spectrometer (TOMS) onboard consecutive Nimbus 7 (1/11/1978-6/5/1993), Meteor-3 (22/8/1991-24/11/1994), and Earth Probe (22/7/1996-14/12/2005) satellites followed with the Ozone Monitoring Instrument (OMI) onboard Aura (1/10/2004 onward) have almost continuously measured UV radiances backscattered from the Earth. Surface UV irradiances have been estimated using the TOMS UV algorithm for the same wavelengths centered at 305, 310, 324, and 380 with a $0.55 \mathrm{~nm}$ (FWHM) triangular SRF (Herman et al., 1996, 1999; Krotkov et al., 1998, 2002; Tanskanen et al., 2007).

Satellite retrievals, desired for their daily contiguous global coverage, have been compared with ground-based spectrometer measurements at a limited number of sites (McKenzie et al., 2001; Fioletov et al., 2002, 2004; Tanskanen et al., 2007). The UVMRP narrow filter measurements (Bigelow et al., 1998; DeLuisi et al., 2003; Slusser et al., 2002) provide an additional opportunity for satellite estimated irradiance validation that has not yet been fully explored. Previous comparisons, while essential, cannot provide a systematic assessment of how the retrieval biases depend on spectral wavelengths and which sources are likely responsible (Wuttke et al., 2003). A few studies have compared TOMS irradiance retrievals with ground measurements for specific wavelengths at several sites and limited time periods. These include Slusser et al. (2002) for 305 and $368 \mathrm{~nm}$ at 2 UVMRP sites (NM02, OK02) in the US, Fioletov et al. (2002) for 305 and $324 \mathrm{~nm}$ at 10 sites in Canada, Kazantzidis et al. (2006) for 305, 310, and $324 \mathrm{~nm}$ at 4 stations in Europe, Kazadzis et al. (2009a) for 305, 324, and $380 \mathrm{~nm}$ at a European station, and Buchard et al. (2008) for 324 and $380 \mathrm{~nm}$ at a French site.

None of the existing studies has systematically compared the TOMS retrievals and UVMRP measurements of surface spectral UV irradiances at all matching wavelengths and available sites with long-term records. In particular, TOMS operational UV irradiances differ from UVMRP measurements in the center wavelength and/or SRFs of the spectral bands, making their direct comparison difficult and inconsistent. Thus, this study first applied a radiative transfer model to convert TOMS UV retrievals toward the center wavelengths $(305,311,325$ and $368 \mathrm{~nm})$ and SRFs of UVMRP measurements. The results were then compared at 27 UVMRP sites over the continental US that have long-term records ( $>4$ years) of high-quality data. The comparison fur- ther considers local air pollution conditions $\left(\mathrm{NO}_{2}\right.$ and $\left.\mathrm{SO}_{2}\right)$ derived from satellites and uses two cloud screening methods to better identify the likely sources that are responsible for TOMS biases. These are the major aspects of this study that facilitate a more objective assessment and better understanding of TOMS retrieval biases in terms of their regional dependencies on spectral wavelengths, cloud conditions, and aerosol loadings.

In general, the biases of TOMS from UVMRP surface spectral UV irradiances can be attributed to four major sources: (1) retrieval uncertainties in the TOMS UV algorithm (Herman et al., 1999; Krotkov et al., 2001); (2) SRF differences (2-nm FWHM measured SRF vs. 0.55-nm analytical triangular SRF); (3) inhomogeneity effects due to large spatial and temporal variability of aerosols and clouds within a satellite pixel or TOMS grid (Herman et al., 1999; Weihs et al., 2008; Kazadzis et al., 2009b); and (4) systematic TOMS overestimations resulting from tropospheric UVabsorbing aerosols (Papayannis et al., 2005; Amiridis et al., 2005; Li et al., 2009) and tracer gases (e.g., $\mathrm{NO}_{2}, \mathrm{SO}_{2}$, and tropospheric $\mathrm{O}_{3}$ ) (Zerefos et al., 2002) that were not fully incorporated in the TOMS UV algorithm (Krotkov et al., 1998; Herman et al., 1999; McKenzie et al., 2001; Fioletov et al., 2002; Kazantzidis et al., 2006; Tanskanen et al., 2007). Since source (1) is beyond the scope of this study, we attempt to address the other three sources. In particular, a re-convolution approach is developed in Sect. 3 to match the MFRSR SRFs and a new cloud screening methods is incorporated in Sect. 4 to reduce the inhomogeneity effects. The results are first compared under clear-sky conditions in Sect. 5 to determine the dependence of TOMS biases on SRFs, aerosol loadings, and geographic regions; the cloud effects are then examined in Sect. 6. In summary, the intention of this study is to provide a more complete understanding of the TOMS UV retrieval biases as concluded in Sect. 7.

\section{Surface UV irradiances from UVMRP measurements and TOMS retrievals}

The UVMRP data used in this study include the surface spectral global (direct sun plus diffuse sky) UV irradiance measured by the MFRSRs every $20 \mathrm{~s}$ and averaged to 3-min intervals (Bigelow et al., 1998), as well as the on-site total (aerosol + cloud) optical depth (TOD) retrieved by the Langley regression method (Harrison and Michalsky, 1994). Under clear-sky conditions the TOD equals the aerosol optical depth (AOD). The uncertainty for UV-MFRSR summertime lamp calibrated irradiance used in the present study is estimated at $\pm 5.2 \sim \pm 8 \%$ (Slusser et al., 2002; Krotkov et al. 2005a).

In comparison, the TOMS data used in this study include the retrieved surface noon spectral UV irradiances and the modified Lambert effective TOMS reflectivity (MLER), available over the globe at $1^{\circ} \times 1^{\circ}$ grid spacing once per day 
near local solar noon. The reflectivity approximates surface albedo under clear-sky conditions including backscatter from aerosols. In the presence of clouds, the MLER is a weighted sum of the cloudy and clear parts. The surface irradiances are retrieved from TOMS measured backscattered UV (BUV) radiances by the TOMS UV algorithm version 8 (Herman et al., 1999; Krotkov et al., 1998, 2001). The main objective of the present study is a rigorous assessment and better understanding of the biases in the TOMS UV retrievals against the UVMRP measurements at all matching wavelengths (305, $311,325,368 \mathrm{~nm}$ ).

Note that the TOMS retrievals and UVMRP ground measurements differ in spatial and temporal resolutions. The ground measurements reflect the local conditions close to the monitoring sites and provide nearly continuous time coverage, while the satellite retrievals represent the average condition in an area of about $100 \mathrm{~km} \times 100 \mathrm{~km}$ but only at noon. Following previous studies (e.g., Slusser et al., 2002; Fioletov et al., 2002, 2004; Kazantzidis et al., 2006; Antón et al., 2007), the UVMRP 3-min measurements were averaged within $\pm 1 \mathrm{~h}$ of the satellite overpass at noon as a first-order approximation to account for the spatial resolution difference at the time of TOMS overpass. Note also that it is difficult for TOMS to distinguish clouds from snow on the ground, causing well-known underestimations of surface irradiances (Krotkov et al., 2002). Thus, this study focuses on the summertime (May through September) to avoid possible contamination by snow cover at northern high-altitude sites.

This study evaluates the most recent TOMS retrievals (with the latest correction in 2007 for sensor degradation) from the Earth Probe satellite, which provided the longest continuous data records overlapping with the UVMRP measurements. Specifically, the comparison period was from May 2000 to May 2004. After 2004, the TOMS UV retrievals were not available due to calibration problems, whereas before 2000, many UVMRP sites did not start measurements of surface spectral UV irradiance and/or concurrent cloud detections (see Sect. 4). Among the total 36 UVMRP climatological sites, 3 are located in Alaska, Hawaii, and New Zealand; 5 started after 2006; and 1 closed in 2001. Thus, only 27 sites located in the continental US and the adjacent US-Canadian border were used in the comparison. Table 1 lists their site specifications, including brief descriptions. These sites are listed in the order of 6 climatic regions (Northwest-Rocky Mountain, Southwest, Central Plains, Midwest, Northeast, and Southeast) arranged from north to south and then from west to east. Within each region, the sites are listed in the order of increasing mean AOD values. The geographical distribution map for the monitoring sites can be found at the UVMRP website (http://uvb.nrel.colostate.edu/UVB/uvb_network.jsf).

\section{Spectral re-convolution from TOMS to UVMRP bands}

Because the center wavelength and/or SRF of the surface UV irradiances differ between TOMS and UVMRP, a spectral reconvolution is necessary to ensure a consistent comparison. Moreover it is unpractical and difficult for TOMS to generate the operational UV products using the center wavelengths and SRFs of MFRSR instruments to directly compare with UVMRP data, since the SRFs of MFRSR measured by the CUCF are changed annually and different for each instrument. This study chose to re-convolute the TOMS retrievals with the center wavelength and SRF identical to UVMRP measurements. The re-convolution is implemented by multiplying the TOMS UV irradiances with the SRF scaling factors as calculated below:

$\alpha\left(\lambda_{T}, \lambda_{U}\right)=\int R(\lambda) S_{U}\left(\lambda-\lambda_{U}\right) d \lambda / \int R(\lambda) S_{T}\left(\lambda-\lambda_{T}\right) d \lambda(1)$

where $S$ is the SRFs of the TOMS and UV-MFRSR, $R(\lambda)=C M F \times R_{c}(\lambda), C M F$ is the cloud modification factor, and $R_{c}(\lambda)$ is the clear-sky spectral irradiance modeled by DISORT (discrete ordinate radiative transfer) (Stamnes et al., 1988) with 32 streams and $0.1 \mathrm{~nm}$ spectral resolution ranging from 280 to $420 \mathrm{~nm}$. Since the TOMS retrieval algorithm accounts for the effect of non-absorbing aerosols (Krotkov et al., 1998; Tanskanen et al., 2007), the single scattering albedo is set to 1.0 in the $R_{c}(\lambda)$ calculation. $S_{T}$ is the triangular spectral response function $(0.55 \mathrm{~nm}$ FWHM $)$ of the TOMS retrievals and $S_{U}$ is the actual spectral response function ( $2 \mathrm{~nm}$ FWHM) of UVMRP measurements. $\lambda_{T}$ is the center wavelength in TOMS retrievals $(305,310,324$, $380 \mathrm{~nm})$ and $\lambda_{U}$ is the effective wavelength of the UVMRP measurements $(305,311,325,368 \mathrm{~nm})$.

The SRF scaling factor lookup tables were generated from Eq. (1) by the UV spectra $R(\lambda)$ estimated from DISORT in terms of varying total column ozone (200-500 DU) and solar zenith angle (0-90 degrees). Calculations showed that the scaling factors are not sensitive to non-absorbing aerosol optical depth (AOD) (relative differences of $\alpha$ are within 2\%). Thus, the dependence of $\alpha$ on AOD caused a minor effect on the comparisons and was not included. The scaling factors were interpolated from the lookup tables based on the specific column ozone derived from the TOMS and the solar zenith angle determined by the geophysical information at the UVMRP site. Following the MLER cloud correction method of TOMS UV algorithm (Krotkov et al., 2001; Tanskanen et al., 2007), this study assumes that cloud modification factor $C M F$ is independent of wavelength. As such, the SRF scaling factor is identical between clear and cloudy sky conditions, and the $C M F$ is no longer needed for the $\alpha$ derivation in Eq. (1).

Figure 1 illustrates the variations of the scaling factors for the TOMS spectral irradiances at the UVMRP site IL02 at Bondville, Illinois in July 2003. As total column ozone 
Table 1. The geographical information and brief descriptions of 27 UVMRP observation sites. The geographical distribution map for the monitoring sites can be found at the UVMRP website (http://uvb.nrel.colostate.edu/UVB/uvb_network.jsf).

\begin{tabular}{|c|c|c|c|c|c|}
\hline Region & Name & Latitude $\left({ }^{\circ}\right)$ & Longitude $\left({ }^{\circ}\right)$ & Elevation $(\mathrm{m})$ & Location \\
\hline \multirow[t]{6}{*}{ Northwest-Rocky Mountain } & UT02 & 41.666 & -111.891 & 1368 & Utah Climate Center, Logan, Utah \\
\hline & WA02 & 46.750 & -117.183 & 804 & $\begin{array}{l}\text { Albion Field Station, Pullman, Washing- } \\
\text { ton }\end{array}$ \\
\hline & SK02 & 50.197 & -104.700 & 580 & $\begin{array}{l}\text { Bratt's Lake Observatory [roof], Regina, } \\
\text { Saskatchewan }\end{array}$ \\
\hline & $\mathrm{CO} 02$ & 40.792 & -104.755 & 1641 & $\begin{array}{l}\text { Central Plains Experimental Range, } \\
\text { Nunn, Colorado }\end{array}$ \\
\hline & MT02 & 48.310 & -105.100 & 634 & $\begin{array}{l}\text { Fort Peck Assiniboine and Sioux Tribes, } \\
\text { Poplar, Montana }\end{array}$ \\
\hline & $\mathrm{CO} 12$ & 40.450 & -106.734 & 3220 & $\begin{array}{l}\text { DRI Storm Peak Lab [roof], Steamboat } \\
\text { Springs, Colorado }\end{array}$ \\
\hline \multirow[t]{5}{*}{ Southwest } & CA22 & 32.806 & -115.444 & -18 & $\begin{array}{l}\text { UC Desert Research and Extension Cen- } \\
\text { ter, Holtville, California }\end{array}$ \\
\hline & $\mathrm{CA} 02$ & 38.529 & -121.761 & 18 & $\begin{array}{l}\text { UC Davis Climate Station, Davis, Califor- } \\
\text { nia }\end{array}$ \\
\hline & NM02 & 32.617 & -106.742 & 1317 & $\begin{array}{l}\text { Jornada Experimental Range, Las Cruces, } \\
\text { New Mexico }\end{array}$ \\
\hline & TX02 & 29.133 & -103.517 & 670 & $\begin{array}{l}\text { Castolon Site at Big Bend National Park, } \\
\text { Panther Junction, Texas }\end{array}$ \\
\hline & AZ02 & 36.058 & -112.183 & 2073 & $\begin{array}{l}\text { Abyss Site at Grand Canyon National } \\
\text { Park, Flagstaff, Arizona }\end{array}$ \\
\hline \multirow[t]{2}{*}{ Central Plains } & NE02 & 41.133 & -96.483 & 353 & $\begin{array}{l}\text { High Plains Regional Climate Center, } \\
\text { Mead, Nebraska }\end{array}$ \\
\hline & OK02 & 36.617 & -97.500 & 317 & $\begin{array}{l}\text { US Department of Energy } \\
\text { ARM/SGP/CART, Billings, Oklahoma }\end{array}$ \\
\hline \multirow[t]{5}{*}{ Midwest } & MI02 & 45.555 & -84.666 & 238 & $\begin{array}{l}\text { University of Michigan Biological Sta- } \\
\text { tion, Pellston, Michigan }\end{array}$ \\
\hline & MN02 & 47.181 & -93.533 & 394 & $\begin{array}{l}\text { North Central Research and Outreach } \\
\text { Center, Grand Rapids, Minnesota }\end{array}$ \\
\hline & WI02 & 44.708 & -89.766 & 381 & Lake Dubay, Dancy, Wisconsin \\
\hline & IN02 & 40.475 & -86.992 & 216 & $\begin{array}{l}\text { Agronomy Center for Research and Edu- } \\
\text { cation, West Lafayette, Indiana }\end{array}$ \\
\hline & IL02 & 40.045 & -88.368 & 213 & $\begin{array}{l}\text { Environmental and Atmospheric Re- } \\
\text { search Site, Bondville, Illinois }\end{array}$ \\
\hline \multirow[t]{4}{*}{ Northeast } & NY02 & 42.876 & -77.029 & 218 & $\begin{array}{l}\text { Agricultural Experiment Station at } \\
\text { Geneva, Geneva, New York }\end{array}$ \\
\hline & ON02 & 43.780 & -79.470 & 198 & $\begin{array}{l}\text { Environment Canada building [roof], } \\
\text { Toronto, Ontario }\end{array}$ \\
\hline & ME12 & 46.681 & -68.038 & 144 & $\begin{array}{l}\text { Northern Maine Regional Office, Presque } \\
\text { Isle, Maine }\end{array}$ \\
\hline & VT02 & 44.533 & -72.856 & 408 & $\begin{array}{l}\text { Proctor Maple Research Center, Burling- } \\
\text { ton, Vermont }\end{array}$ \\
\hline \multirow[t]{5}{*}{ Southeast } & MD02 & 38.916 & -76.149 & 5 & $\begin{array}{l}\text { Wye Research and Education Center, } \\
\text { Queenstown, Maryland }\end{array}$ \\
\hline & GA02 & 33.181 & -84.410 & 270 & $\begin{array}{l}\text { University of Georgia Bledsoe Research } \\
\text { Farm, Griffin, Pike, Georgia }\end{array}$ \\
\hline & LA02 & 30.358 & -91.166 & 7 & $\begin{array}{l}\text { LSU Central Research Station, Baton } \\
\text { Rouge, Louisiana }\end{array}$ \\
\hline & MS02 & 33.469 & -88.782 & 85 & $\begin{array}{l}\text { Agricultural and Forestry Experiment } \\
\text { Station, Starkville, Mississippi }\end{array}$ \\
\hline & FL02 & 25.383 & -80.683 & 0 & $\begin{array}{l}\text { Beard Research Center at Everglades } \mathrm{Na}- \\
\text { tional Park, Homestead, Florida }\end{array}$ \\
\hline
\end{tabular}



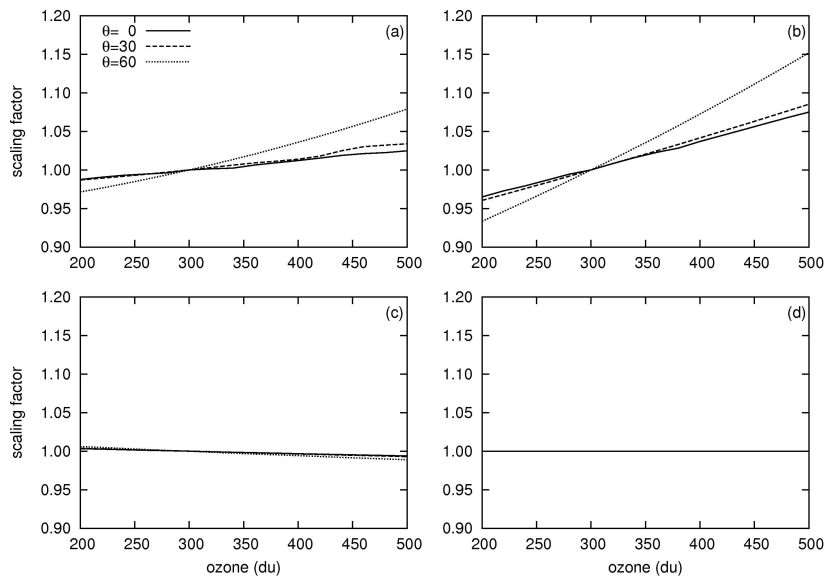

Fig. 1. Scaling factors for the re-convolution of the TOMS spectral irradiances at (a) $305 \mathrm{~nm}$, (b) $310 \mathrm{~nm}$, (c) $324 \mathrm{~nm}$, and (d) $380 \mathrm{~nm}$ to the UVMRP measurements at in Bondville, IL (IL02) in July, 2003 in terms of the total column ozone for the range of 200-500 DU and three solar zenith angles $(0,30,60$ degrees $)$. The scaling factors were normalized by the corresponding values of $300 \mathrm{DU}$ ozone.

increases, the scaling factors increase for 305 and $311 \mathrm{~nm}$, decrease slightly for $325 \mathrm{~nm}$, and remain nearly constant for $368 \mathrm{~nm}$. The positive dependence of the scaling factors on total column ozone for 305 and $311 \mathrm{~nm}$ increases when the solar zenith angle increases. Note that the result shown was normalized to an ozone concentration of $300 \mathrm{DU}$.

\section{Detection of clear versus cloudy sky conditions}

To separate the cloud effects from other sources in explaining the TOMS biases, a robust clear-sky identification method is required. The conventional method was based on the TOMS measured reflectivity at 380 or $360 \mathrm{~nm}$; when this value is smaller than a threshold, the grid is identified as a clear-sky condition. Such a method, hereafter referred to as TRT (TOMS reflectivity threshold), has two important drawbacks, both of which were caused by the substantially larger area size of a TOMS retrieval grid than an area around the UVMRP monitoring site. First, the choice for the threshold was subjective, ranging from small values around 0.070.08 (Eck et al., 1995; Herman and Celarier, 1997; Wang et al., 2000) to significantly larger ones as 0.2 (Fioletov et al., 2002). Our analysis indicated that a threshold of 0.07 would identify very few grid-wide clear-sky days. Thus the larger threshold of 0.2 as used in the recent studies was adopted for the comparison. Second, since the TOMS reflectivity represents the average condition over an entire grid cell, the use of a large threshold may allow for fractional clouds within the grid. Kazadzis et al. (2009b) demonstrated that the UV irradiance differences among three sites within a single OMI pixel were up to $100 \%$ under partial clouds. Weihs et al. (2008) also showed that, within one OMI pixel,
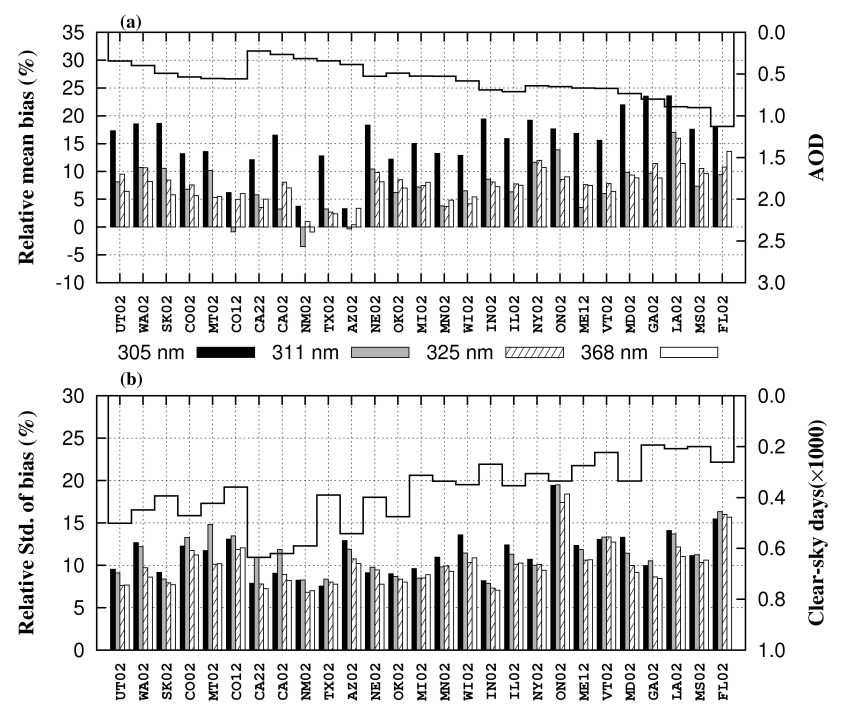

Fig. 2. The relative mean (a) and standard deviation (b) of biases (left axis) of the 2000-2004 summer (May-September) noontime surface UV irradiances at 305, 311, 325, and $368 \mathrm{~nm}$ under clearsky conditions using the TRT (TOMS reflectivity threshold) cloud screening method during 2000-2004. Also shown as the top curves (right axis) are total optical depth (aerosol plus cloud) at $368 \mathrm{~nm}$ (a) and total number of clear-sky days (b).

the UV erythemal dose deviated up to as much as $\pm 10 \%$ under partial cloud covers and differed by $20 \%$ due to the AOD spatial variability alone.

This study, therefore, incorporates a new cloud screening method based on Long and Ackerman (2000) to better detect clear-sky conditions (hereafter referred to as L\&A). The method was previously implemented by $\mathrm{Xu}$ et al. (2006) to isolate clear-sky conditions for evaluating radiative transfer model performance against the UVMRP measurements. In contrast to the region-specific and subjective TRT method, the L\&A technique is site-specific and objective as it utilizes both global and diffuse surface downwelling broadband solar irradiances measured by UVMRP VIS-MFRSR at the unfiltered silicon photodiode band (Bigelow et al., 1998). The technique involves four individual tests for the total and diffuse shortwave irradiances. Only the measurements that pass all four tests are identified as representing clear-sky conditions. The L\&A method can effectively eliminate all cloudy cases that were observed on-site by the MFRSR. It is, however, too restrictive such that clear skies with haze can also be excluded, causing the result biased toward low aerosol loading cases (Augustine et al., 2008). The comparison results of the TRT and L\&A methods are presented in Sect. 6. 


\section{Spectral, aerosol, and regional dependences of clear-sky irradiance biases}

Figure 2 illustrates the relative mean $R M=M D / M_{\text {TOMS }}$ and deviation $R D=S D / M_{\mathrm{TOMS}}$ statistics of the noontime spectral $(305,311,325,368 \mathrm{~nm})$ irradiance differences between TOMS retrievals and UVMRP measurements at 27 sites under clear-sky conditions using the TRT cloud screening method during the summer periods (May-September) of 2000-2004. Here $M D$ and $S D$ are the temporal mean and standard deviation of the TOMS minus UVMRP daily differences; and $M_{\text {TOMS }}$ is the mean of all TOMS daily irradiances. The use of the TOMS rather than the UVMRP mean as the denominator for normalization is mainly to facilitate the result comparison with previous studies. The $R M$ statistic measures the systematic tendency of TOMS biases, while the $R D$ statistic depicts the corresponding fluctuations due to local variability of aerosol loading (Arola et al., 2005), air pollution, and cloud contamination (Kazantzidis et al., 2006). Also shown are total (aerosol+cloud) optical depth (equivalent to AOD for a clear sky) and the total number of clear-sky days (i.e., samples used in the above statistics).

Figure $2 \mathrm{a}$ shows that the TOMS clear-sky irradiances contain systematic positive biases $<20 \%$ for $305 \mathrm{~nm}$ and $<10 \%$ for longer wavelengths at nearly all monitoring sites. When averaged over 27 UVMRP sites, $R M$ for $305,311,325$, and $368 \mathrm{~nm}$ are respectively $15.4,7.9,7.6$, and $7.0 \%$ (Table 2). To our knowledge, only four other studies have compared TOMS/OMI UV retrieval biases among spectral bands. Fioletov et al. (2002) showed average TOMS clearsky biases of $11.9 \%$ for $305 \mathrm{~nm}$ and $9.5 \%$ for $324 \mathrm{~nm}$ relative to ground-based Brewer UV spectrometers at 10 Canadian sites; Kazantzidis et al. (2006) estimated the OMI total-sky (clear and cloudy) biases from 4 European sites as 19.4, 15.8, and $11.0 \%$ for 305,310 , and $324 \mathrm{~nm}$ respectively; Buchard et al. (2008) obtained the clear-sky biases at one French site as $6.4 \%$ and $3.7 \%$ for 324 and $380 \mathrm{~nm}$; Kazadzis et al. (2009a) calculated the OMI biases at one Greece site for 305, 324, and $380 \mathrm{~nm}$ as 21.3, 13.0, 9.9\% for clear-sky and 23.1, 14.5, $11.5 \%$ for total-sky conditions, respectively. Our results compared well to those other findings.

Figure $2 \mathrm{~b}$ depicts the relative bias deviations $R D$ falling below $15 \%$ at all sites except for ON02 and FL02; smaller values $(<10 \%)$ are obtained at SK02, UT02, NM02, TX02, NE02, OK02, MI02, and IN02. The RD averaged over 27 sites have a small range among the 4 wavelengths from 11.4 to $9.9 \%$ (Table 2), indicating that the fluctuations due to local daily variability are similar across the UV spectral range.

Two important conclusions from Fig. 2 require more comprehensive diagnosis to understand their causes. First, TOMS biases of clear-sky surface UV irradiances exhibit significant spectral contrasts, where overestimation for $305 \mathrm{~nm}$ is approximately twice that of those for other bands. Second, the biases also reveal substantial variations across the monitoring sites, with a strong regional dependence. While
TOMS bias dependence on location was mentioned in previous studies (Fioletov et al., 2004), the spectral differences reported here are larger (comparing with Fioletov et al. (2002) and Kazantzidis et al., 2006). We will examine the biases in more details in the following sections to identify the likely explanation.

\subsection{Data compatibility issues}

Surface UV measurements were taken at the ground mainly by two types of instruments: filter MFRSR and Brewer spectrophotometers. The previous TOMS UV retrieval product (version 7) was used widely against ground-based UV measurements before August, 2004 when the version 8 data was released. To facilitate the comparison of the TOMS retrieval biases (with different TOMS UV products) against MFRSR and Brewer measurements, we considered specific sites in Canada (ON02, Toronto; SK02, Regina, $3.14 \mathrm{~km}$ ) that had measurements from both instruments and also available TOMS-Brewer comparisons in the literature. Fioletov et al. (2002) showed that the clear-sky TOMS-Brewer biases for 305 and $324 \mathrm{~nm}$ are respectively 14.5 and $10.1 \%$ at ON02, and $10.6 \%$ and $9.5 \%$ at SK02. The corresponding TOMSMFRSR biases from this study are $17.6 \%$ and $8.5 \%$ at ON02, and $18.6 \%$ and $8.4 \%$ at SK02. Except for $305 \mathrm{~nm}$ at SK02, the biases between TOMS-Brewer and TOMS-MFRSR are similar (within 3\%). They can be attributed to instrument calibration uncertainties, about 6\% for the Brewer (Sabburg et al., 2002) and 5-8\% for the MFRSR (Slusser et al., 2002).

The larger difference $(8 \%)$ between the TOMS-Brewer and TOMS-MFRSR biases for $305 \mathrm{~nm}$ at SK02 is not likely caused by a different sky view or topographic effects, since the instruments are located on flat terrain with a distance of only $3.14 \mathrm{~km}$. We speculate that it may result from the use of the different TOMS retrieval products, between versions 7 for Fioletov et al. (2002) and 8 for this study. Given the lack of direct comparison in spectral irradiances, an estimate may be made from the comparison of erythemal irradiances between the TOMS versions and Brewer measurements. Since the erythemal irradiance is integrated from the UV spectrum with larger weights at short wavelengths $<310 \mathrm{~nm}$ (McKinlay and Diffey, 1987), the difference of TOMS-Brewer erythemal irradiance biases between versions 7 and 8 is a reasonable approximate for that at $305 \mathrm{~nm}$. The total-sky erythemal radiation bias at SK02 is $12 \%$ for version 8 (Fioletov et al., 2004), which is significantly larger than $7.9 \%$ for version 7 (Fioletov et al., 2002).

\subsection{Spectral dependence}

The relative mean biases $R M$ at $305 \mathrm{~nm}$ are systematically higher than the other three spectral bands at all sites (Fig. 2a), with average enhancement factors of 1.9, 2.0, and 2.2 relative to the $311 \mathrm{~nm}, 325 \mathrm{~nm}$, and $368 \mathrm{~nm}$, respectively. The correlation coefficients among the 27 sites between $R M$ at 
Table 2. Averaged relative mean biases $(R M)$ and the relative deviation $(R D$, in parenthesis) at $305,311,325$, and $368 \mathrm{~nm}$ across all 27 sites under clear-sky and total-sky conditions (* excluding the remote and clean sites, NM02, AZ02, and CO12, ** excluding sites CA22, FL02, GA02, and ON02 to be compared with the results of L\&R).

\begin{tabular}{llllll}
\hline Sky condition & Cloud screening method & $305 \mathrm{~nm}$ & $311 \mathrm{~nm}$ & $325 \mathrm{~nm}$ & $368 \mathrm{~nm}$ \\
Clear-sky & TRT & $15.4(11.4)$ & $7.9(11.4)$ & $7.6(10.2)$ & $7.0(9.9)$ \\
& TRT* & $16.8(11.4)$ & $9.0(11.4)$ & $8.3(10.2)$ & $7.5(9.9)$ \\
& TRT** & $15.0(11.0)$ & $7.4(10.9)$ & $7.4(9.7)$ & $6.6(9.4)$ \\
& L\&R & $11.5(8.8)$ & $3.5(8.5)$ & $4.0(7.2)$ & $3.0(6.5)$ \\
Total-sky & Total-sky & $16.5(16.9)$ & $9.5(16.9)$ & $8.5(16.0)$ & $7.8(16.0)$ \\
& Total-sky* & $17.6(17.0)$ & $10.4(17.1)$ & $8.8(16.2)$ & $8.0(16.2)$ \\
\hline
\end{tabular}

$305 \mathrm{~nm}$ and other bands are $0.82,0.86$, and 0.75 , suggesting a strong spatial coherence that persists across the UV spectral ranges. Thus, the sources responsible for the TOMS biases must be common to all sites, but also amplified near $305 \mathrm{~nm}$. One obvious candidate is the absorbing aerosols, which have important effects on surface irradiances across all UV spectral ranges while increasing their absorption cross section at shorter wavelengths (Krotkov et al., 2005b; Arola et al., 2005; Kazantzidis et al., 2006). The current TOMS UV algorithm corrects only the effects of elevated plumes of smoke and dust detectable by the TOMS absorbing Aerosol Index (AI) data (Krotkov et al., 1998)), but does not account for other boundary layer aerosol absorption effects, and thus likely overestimates surface irradiances at locations in which absorbing aerosols are abundant with the expected amplification at $305 \mathrm{~nm}$. Unfortunately, there were no concurrent measurements of absorbing aerosol optical thickness or known aerosol properties at MFRSR sites to confirm that.

Another possible contributing source of the bias is UV absorption by tropospheric pollutant trace gases, including $\mathrm{SO}_{2}$ (Krotkov et al., 2006; Fioletov et al., 2002) and tropospheric $\mathrm{O}_{3}$ (Brühl and Crutzen, 1989), that is strong at $305 \mathrm{~nm}$ but negligible at longer wavelengths (Fioletov et al., 2002). Should this be the case, the $R M$ differences between 305 and $368 \mathrm{~nm}$ may depict the effects of trace gases on the surface irradiances at $305 \mathrm{~nm}$ that were not included in the TOMS UV algorithm. The differences are especially large $(12-15 \%)$ at sites SK02, GA02, LA02, IN02, and MD02, as compared with the average of $7 \%$ over the remaining sites. These sites are located near heavy air pollution areas where high concentrations of trace gases are present in the boundary layer.

Figure 3 compares the $R M$ differences between 305 and $368 \mathrm{~nm}$ with total tropospheric $\mathrm{SO}_{2}$ abundances. Given the lack of concurrent data covering the whole US at any specific time, the climatological summer (May-September) mean $\mathrm{SO}_{2}$ geographic distributions were constructed from the available years (2004-2008) of the SCIAMACHY (Scanning Imaging Absorption Spectrometer for Atmospheric Chartography) monthly retrievals at a grid spacing of $0.25^{\circ}$ $(\sim 27.5 \mathrm{~km})$ (TEMIS, 2006$)$. They were bilinearly interpo-

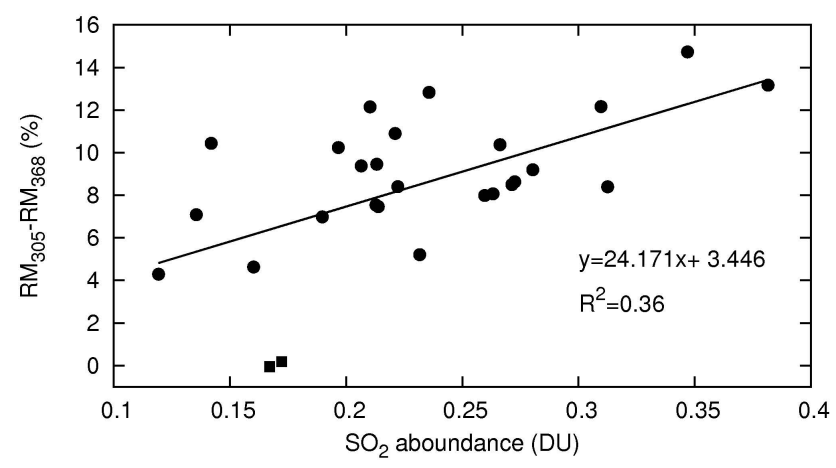

Fig. 3. The scatter diagram of the $R M$ differences (\%) between 305 and $368 \mathrm{~nm}$ versus the climatological mean total tropospheric abundances (DU) of $\mathrm{SO}_{2}$ (solid points) for the 27 UVMRP. Also shown are the respective linear regression function and correlation coefficient, with the fitting line for $\mathrm{SO}_{2}$ (solid). Two high elevation sites (AZ02, CO12) are distinguished by squares because of doubt on $\mathrm{SO}_{2}$ abundance by data interpolation.

lated to obtain the total $\mathrm{SO}_{2}$ abundances at all UVMRP sites. Figure 3 shows a definite positive correspondence between the $R M$ differences and $\mathrm{SO}_{2}$ abundances, with a correlation coefficient of 0.6. This is statistically significant at the $99 \%$ confidence level ${ }^{1}$, suggesting that the $\mathrm{SO}_{2}$ effect plays a notable role in the bias enhancement at $305 \mathrm{~nm}$ and the variance of the $\mathrm{SO}_{2}$ explains $36 \%$ variance of the $R M$ differences. Note that there are two high altitude sites (square points in Fig. 3) located on the top of mountains at the elevation of $3220 \mathrm{~m}$ (CO12) and $2073 \mathrm{~m}$ (AZ02) where the satellite retrieved total $\mathrm{SO}_{2}$ abundances may have big uncertainties. The correlation coefficient remains 0.6 if excluding two sites, but increases to 0.8 if assuming their $\mathrm{SO}_{2}$ abundance close to background level (near zero) because of a generally clean environment at high elevations.

1 Assuming independence between data from different sites, there are 25 degrees of freedom and the corresponding threshold for correlations to be statistically significant at the $95 \%$ (99\%) confidence level is $0.38(0.49)$. 
Table 3. The correlation coefficients across all 27 sites of the clearsky relative mean biases $(R M)$ at $305,311,325$, and $368 \mathrm{~nm}$ with the major tropospheric trace gases $\left(\mathrm{NO}_{2}\right.$ and $\left.\mathrm{SO}_{2}\right)$ and aerosol optical depth from UVMRP and aerosol absorbing optical depth from OMI.

\begin{tabular}{|c|c|c|c|c|}
\hline$R M$ & $305 \mathrm{~nm}$ & $311 \mathrm{~nm}$ & $325 \mathrm{~nm}$ & $368 \mathrm{~nm}$ \\
\hline $\mathrm{NO}_{2}$ & 0.42 & 0.41 & 0.30 & 0.34 \\
\hline $\mathrm{SO}_{2}$ & 0.58 & 0.43 & 0.33 & 0.30 \\
\hline AODUVMRP & 0.53 & 0.49 & 0.60 & 0.75 \\
\hline $\mathrm{AAOD}_{\mathrm{OMI}}$ & 0.33 & 0.35 & 0.32 & 0.29 \\
\hline
\end{tabular}

On the other hand, the radiative absorption of the tropospheric $\mathrm{NO}_{2}$ increases gradually from 305 to $368 \mathrm{~nm}$ (Krotkov et al., 2005c). Thus the $\mathrm{NO}_{2}$ absorption cannot directly explain the enhancement of the bias at $305 \mathrm{~nm}$. In addition, $\mathrm{NO}_{2}$ is a key precursor for $\mathrm{O}_{3}$ production generally with strong positive correspondence in rural areas (Seinfeld and Pandis, 1998; Tao et al., 2003), and the $\mathrm{O}_{3}$ absorption increases in the UVB (280-315 nm). Given the lack of data for the tropospheric $\mathrm{O}_{3}$ abundances, $\mathrm{NO}_{2}$ may be used as an indirect measure of the $\mathrm{O}_{3}$ effect on the spectral enhancement. To quantify such contribution, the Global Ozone Monitoring Experiment (GOME) (2000-2003) and SCIAMACHY (2003-2004) monthly retrievals at a grid spacing of $0.25^{\circ}$ $(\sim 27.5 \mathrm{~km})$ (Boersma et al., 2004) were bilinearly interpolated to obtain the total $\mathrm{NO}_{2}$ abundances at all UVMRP sites. Table 3 lists the correlation coefficients of $R M$ with $\mathrm{SO}_{2}$ and $\mathrm{NO}_{2}$ across 27 UVMRP sites for all spectral bands. The $R M$ correlations with the $\mathrm{SO}_{2}$ abundances are 0.58 for $305 \mathrm{~nm}$ and 0.43 for $311 \mathrm{~nm}$, statistically significant at respectively the $99 \%$ and $95 \%$ confidence level. The corresponding correlations with the $\mathrm{NO}_{2}$ abundances are 0.42 and 0.41 , significant at the $95 \%$ confidence level. However, the $R M$ correlations with the $\mathrm{SO}_{2}$ and $\mathrm{NO}_{2}$ abundances for 325 and $368 \mathrm{~nm}$ are insignificant as expected.

Note that the correlation coefficient between the $\mathrm{SO}_{2}$ and $\mathrm{NO}_{2}$ abundances itself is 0.58 , significant at the $99 \%$ confidence level. This positive correspondence may partially explain the medium correlation between $R M$ and $\mathrm{NO}_{2}$ amounts for 305 and $311 \mathrm{~nm}$ and suggest similar emission sources (e.g., power plant emissions) dominating the tropospheric abundances of both pollutants. According to the US Environmental Protection Agency (http://www.epa.gov/ air/emissions/index.htm), the primary $\mathrm{SO}_{2}$ source was from electricity generation at coal-burning power plants that accounted for $71 \%$ of the total US emissions in 2002, while the major $\mathrm{NO}_{2}$ sources were from road vehicles (38\%) and electricity generation (22\%). Since most UVMRP sites are located in agricultural areas, the mobile source is relatively small, and hence the electricity generation may become the dominant source also for $\mathrm{NO}_{2}$.
Kazantzidis et al. (2006) found that TOMS UV retrieval biases under total-sky conditions at 4 European sites gradually decreased as the wavelength increased from 305 to 310 to $324 \mathrm{~nm}$. In contrast, only 2 UVMRP sites (MT02, ON02) were identified with a similar feature under clearsky conditions. Our result averaged from 27 UVMRP sites showed a sharp $R M$ drop (by almost half) from 305 to $311 \mathrm{~nm}$ and small changes beyond that. Even excluding the remote or clean-air sites (their Sondankyla and our NM02, AZ02, CO12) where TOMS biases are considerably low, the result remains significantly different: Kazantzidis et al. (2006) estimated the total-sky biases at 3 sites as $21.9,18.4$, and $13.0 \%$ for 305,310 , and $324 \mathrm{~nm}$, respectively, whereas our clearsky calculations from 24 sites are 16.8, 9.0, 8.3\% at 305, $311,325 \mathrm{~nm}$ (Table 2). This contrast cannot be attributed to the obvious difference between their total and our clear-sky conditions. In fact, our total-sky result (see details in section 6) reveals a similar spectral dependence, with biases of $17.6,10.4$, and $8.8 \%$ for 305,311 , and $325 \mathrm{~nm}$, respectively (Table 2). They are systematically larger than the clear-sky biases across the UV spectral range. We speculate that the contrast in the spectral dependence between the two studies may result from the use of different instruments. Also the uncertainty of the scaling factors for the re-convolution due to total column ozone errors may partially contribute to the above contrast.

\subsection{Aerosol dependence}

Figure 2a also illustrates the mean AODs retrieved at UVMRP sites by the Langley regression method (Harrison and Michalsky, 1994). The correlation coefficients between $R M$ and AODs across 27 sites are 0.53, 0.49, 0.60, and 0.75 for $305,311,325$, and $368 \mathrm{~nm}$, respectively (see Fig. 4). They are statistically significant at the $99 \%$ confidence level. Thus, the TOMS retrieval biases in surface UV irradiances are significantly large at the sites where AODs are high. The largest biases are found at 3 sites near heavy pollution areas, GA02, LA02, and MD02, where the $R M$ values at $305 \mathrm{~nm}$ exceed $20 \%$. On the other hand, there are 3 clean-air sites, AZ02, CO12, and NM02, where small or even negative biases (within $\pm 5 \%$ ) are obtained. Note that the correlation coefficient of $R M$ with AOD increases from $311 \mathrm{~nm}$ to $325 \mathrm{~nm}$ to $368 \mathrm{~nm}$. This indicates the increasing relative contribution of aerosols to the TOMS retrieval biases at the longer wavelengths, where trace gases $\left(\mathrm{SO}_{2}, \mathrm{O}_{3}\right)$ and Rayleigh scattering have a relative smaller effect.

Krotkov et al. (2005b) suggested that TOMS biases should be better correlated with the aerosol absorbing optical depth (AAOD), since the TOMS UV retrieval algorithm does account for aerosol/cloud scattering in the boundary layer. Given the lack of concurrent data, the climatological summer (May-September) mean AAOD values were averaged from daily mean OMI retrievals at $388 \mathrm{~nm}$ of all available years (2004-2008) (Torres et al., 2007). The correlation 


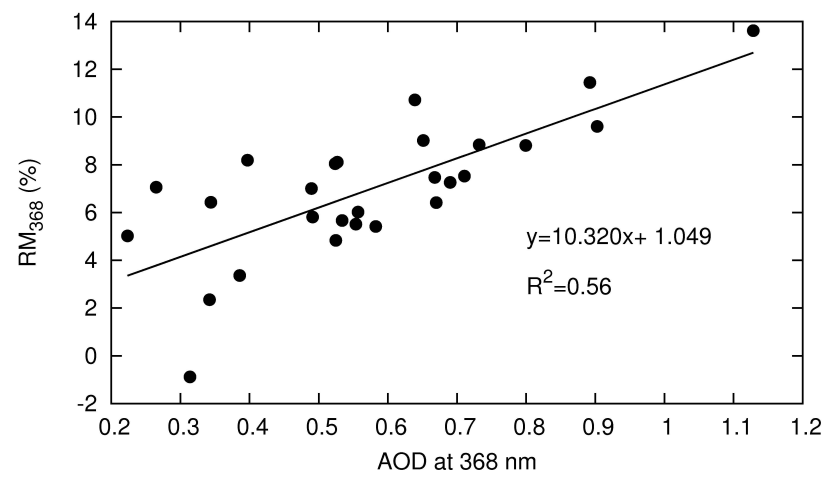

Fig. 4. The scatter diagram of the $R M$ differences (\%) at $368 \mathrm{~nm}$ versus the in-situ mean total optical depth (aerosol plus cloud) at $368 \mathrm{~nm}$ for the 27 UVMRP. Also shown are the respective linear regression function and correlation coefficient, with the fitting line for total optical depth at $368 \mathrm{~nm}$ (solid).

coefficients between TOMS $R M$ and OMI AAOD across the 27 sites are $0.33,0.35,0.32$, and 0.29 for 305,311 , 325 , and $368 \mathrm{~nm}$, respectively (Table 3 ). The corresponding correlation of the $R M$ difference between 305 and $368 \mathrm{~nm}$ with AAOD is only 0.23 . They all are statistically not significant. This weak correspondence may, however, result from weak sensitivity of the OMI AAOD to boundary layer aerosols (Martin, 2008) and other data quality problems (Li et al., 2009), including uncertainties in TOMS irradiance and OMI AAOD retrievals and differences in their data periods. The issue should be revisited when high-quality concurrent AAOD data become available.

Figure 5 compares the temporal correlation coefficients between daily relative differences between TOMS retrievals and UVMRP measurements and AODs at individual sites. Correlations are highly positive, exceeding 0.75 for MT02, CO02, AZ02, ME12, MS02 and FL02; and the medium positive correlations $(0.5-0.7)$ at all other sites except for CA02, OK02, ON02, NE02, and GA02. The relative medium and low correlations at those sites are likely due to the effects of aerosol optical properties such as single scattering albedo or cloud contamination or the uncertainty of UVMRP AODs derived by the Langley regression method (Krotkov et al., 2005a; Corr et al., 2009; Li et al., 2009). Kazantzidis et al. (2001) showed that a decrease of 0.1 in aerosol single scattering albedo decreases the ratio of modeled and measured surface UV irradiance by $7 \%-14 \%$, depending on solar zenith angle. Balis et al. (2004) found that different aerosol types (hence optical properties) can cause surface UV irradiances to differ up to $10 \%$. As discussed in section 6, ON02 and GA02 are also highly contaminated by the presence of partial clouds.

The above result confirms the finding from previous studies that TOMS biases in surface UV irradiances increase with aerosol loadings (Krotkov et al., 1998; McKenzie et al., 2001; Fioeltov et al., 2002; Kazantzidis et al., 2006; Tanska-

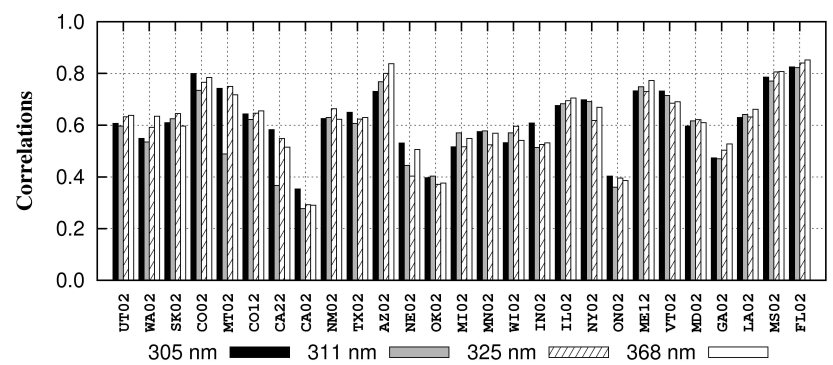

Fig. 5. The temporal correlations of the TOMS irradiance biases from the UVMRP measurements with in-situ optical depths at $368 \mathrm{~nm}$ observed by UVMRP at each monitoring site for 305,311 , 325 , and $368 \mathrm{~nm}$.

nen et al., 2007; Antón et al., 2007; Buchard et al., 2008). This indicates that the TOMS UV algorithm does not fully incorporate the aerosol effects on UV absorption. The net effect may explain nearly $50 \%$ of the variances of the TOMS biases at most sites or across the UVMRP network.

\subsection{Other factors for result limitations}

Since the surface UV radiation is much stronger and more harmful to humans and ecosystems in summer than winter, we focus our comparisons in summertime months. This avoids the snow cover contamination at those northern highaltitude sites in winter. Note that the radiative transfer slant column is longer than in winter than summer due to greater solar zenith angle (SZA). The UV biases in winter could be larger than those in summer if the local conditions (aerosol loading and air pollution) are similar. On the other hand, aerosol loadings and pollutant concentrations are usually smaller in winter than summer and thus may produce smaller UV biases. For example, clear-sky biases for all 4 wavelengths from winter to summer decrease by $6 \%$ at FL02 with small SZA and increase by 3-8\% at CA02 with heavy air pollutions. In consistence with our result, the SZA effects were found to cause various degrees of OMI UV retrieval biases, depending on local conditions (Buchard et al., 2008; Kazadzis et al., 2009b; Antón et al., 2010).

Note that the TOMS UV measurements only available at noontime are not sufficient to resolve rapid diurnal changes in local aerosol loading and air pollution. Our results may be limited by different satellite overpass times for TOMS surface UV irradiances, OMI AODs, and GOME and SCIAMACHY air pollution data. They are also limited to the first-order approximation that averages ground-based measurements (AOD and surface UV irradiances) within $\pm 1 \mathrm{~h}$ of the satellite overpass at noon to account for the spatial and temporal resolution differences between TOMS and MFRSR. The diurnal variations in aerosol loading, air pollution, and cloudiness are expected to cause larger uncertainties on satellite UV daily erythemal dose products than the overpass noontime irradiances analyzed in this study. Martin 
et al. (2000) and Bugliaro et al. (2006) found that the uncertainties on daily dose due to diurnal variations of cloudiness alone were around $20-35 \%$.

\subsection{Regional dependence}

The relative mean biases $R M$ vary greatly among the 27 sites distributed in various climatic regions of the US and Canada (Fig. 2a). The $R M$ ranges from $3.3 \%$ (AZ02) to $23.6 \%$ (LA02) for $305 \mathrm{~nm}$; from $-3.4 \%$ (NM02) to $20.6 \%$ (LA02) for $311 \mathrm{~nm}$; from $0.4 \%$ (AZ02) to $16.0 \%$ (LA02) for $325 \mathrm{~nm}$; and from $-0.9 \%$ (NM02) to $13.6 \%$ (FL02) for $368 \mathrm{~nm}$. The standard deviations of the $R M$ values across the 27 UVMRP sites are 5.1, 5.2, 3.5, and $2.9 \%$ at $305,311,325$, and $368 \mathrm{~nm}$, respectively. They are much larger than those over 10 sites of the Canadian Ozone and Monitoring Network, which were only $1.8 \%$ at $305 \mathrm{~nm}$ and $0.7 \%$ at $324 \mathrm{~nm}$ as shown by Fioletov et al. (2002). As discussed above, the TOMS biases are mainly associated with the abundances of absorbing aerosols and trace gases. The large range of TOMS biases over the UVMRP network results from the large spatial variability of aerosol loadings and air pollution in the US The small range of the TOMS biases over the Canadian network (Fioletov et al., 2002) is likely because all sites are located at high latitudes within a climate region with similar aerosol loadings and air pollution.

Given the above rationale, we can now explain the regional dependence of the TOMS biases, focusing on $305 \mathrm{~nm}$. In the Southeast (LA02, MS02, GA02, FL02, MD02), biases are larger than $20 \%$, highest among the entire UVMRP network. This region is characterized by heavy pollution with large $\mathrm{SO}_{2}, \mathrm{NO}_{2}$ and $\mathrm{O}_{3}$ abundances as well as heavy aerosol loadings along with high humidity enhancing AOD. Aerosols emitted from wildfires in Mexico may also be transported into the region during early summer. These pollutants and aerosols could act to enhance the TOMS biases as their radiative absorption has not been incorporated in the retrieval algorithm. In the Northeast (ON02, NY02, VT02, ME12), biases are above $17 \%$, most likely due to heavy pollution, which may result from local emissions and transports from remote sources in the Midwest and Canada. In the Midwest (MN02, WI02, IL02, MI02, IN02), biases are about $15 \%$, attributed largely to heavy pollution of regional sources. The upwind MN02 site has less bias compared with the downwind IN02, suggesting a certain role of pollutant transport. In the Southwest (CA02, CA22, NM02, AZ02, TX02), with prevailing dry and clear-sky conditions, biases depend mainly on air pollution. At the remote and high altitude AZ02 and NM02 sites with clean air, biases are small, within $\pm 5 \%$. In contrast, at CA02, about 15 miles west of Sacramento, biases are large (16\%). At CA22 and TX02, biases are also large (14\% and $15 \%)$, which may be associated with air pollution emitted from local sources and remotely transported from Mexico. In the Northwest and Rocky Mountain areas (WA02, MT02, CO02, CO12, UT02,
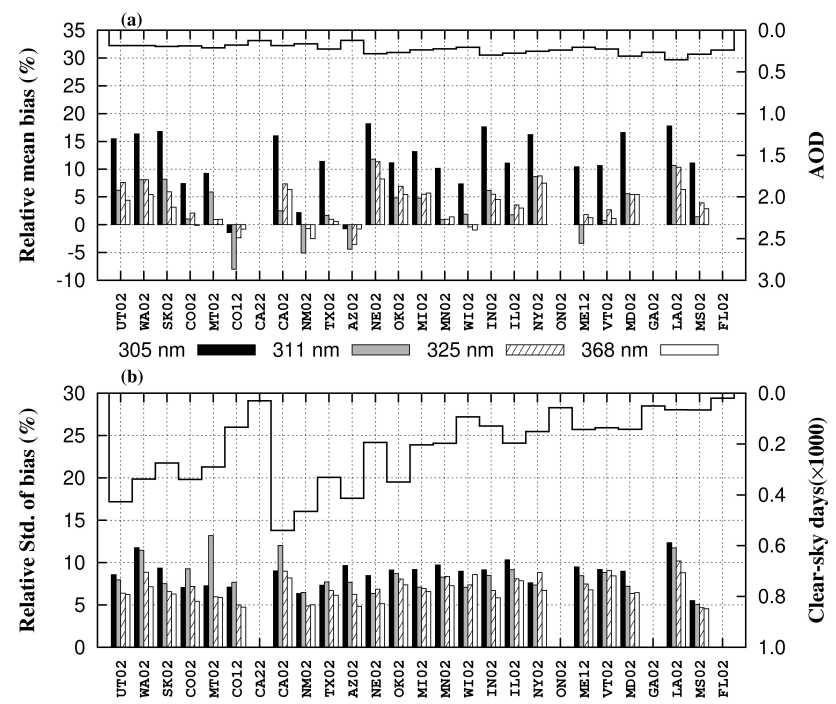

Fig. 6. Same as Fig. 2 except using the L\&A (Long and Ackerman [2000]) cloud screening method.

SK02), biases are possibly influenced by active wildfires and occasional dust transport from Asia. One exception is $\mathrm{CO} 12$, on a mountain top of $3200 \mathrm{~m}$ elevation, where biases are small $(<6 \%)$ as local air is very clean. In the Central Plains (NE02, OK02), biases are likely due to aerosols emitted by regional wildfires and gases transported from polluted areas upwind.

\section{Cloud detection effects and total-sky surface UV}

Figure 6 illustrates the relative mean $R M$ and deviation $R D$ of the noontime spectral $(305,311,325,368 \mathrm{~nm})$ irradiance biases by TOMS retrievals from UVMRP measurements at 27 sites under clear-sky conditions using the L\&A cloud screening method during 2000-2004 summers (May-September). The L\&A method is more restrictive than the TRT method, detecting a much smaller number of clear-sky days. In particular, the number of samples so screened is small $(<60)$, and hence the result is not shown at CA22, FL02, GA02, or ON02. As Fig. 6a is compared with Fig. 2a, the relative mean biases of TOMS are reduced at all monitoring sites and spectral bands. On average over the corresponding 23 sites, the $R M$ reductions for $305,311,325$, and $368 \mathrm{~nm}$ are respectively $3.5,3.9,3.4$, and $3.6 \%$, with little spectral dependence (Table 2).

When the L\&A cloud screening method is used, more monitoring sites and/or spectral bands were identified with small or negative $R M$ biases. They usually are located in remote areas with low aerosol loadings. The cloud contamination using the TRT method can be clearly depicted by the result that AOD in Fig. 2a is substantially larger than those in Fig. 6a. On average over all sites, the clear-sky AOD is 


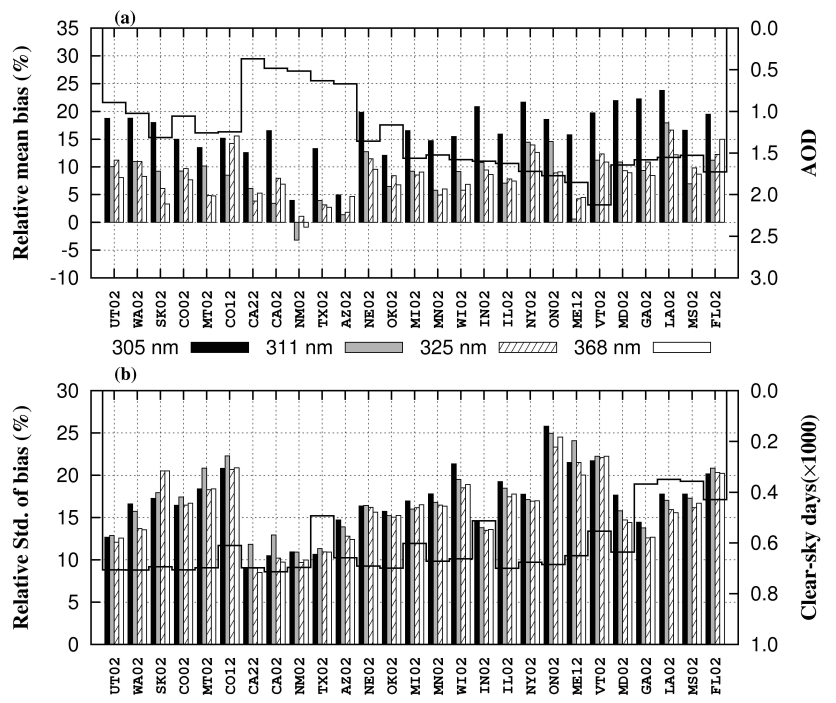

Fig. 7. Same as Fig. 2 except for total-sky conditions.

reduced from 0.58 to 0.23 by using the $L \& A$ rather than the TRT cloud screening method. This suggests that a large portion of the samples may be contaminated by the occurrences of fractional clouds, although not overcast conditions. The reduction is also seen in the relative bias deviations $R D$, which are now 8.8, 8.5, 7.2, and $6.5 \%$, respectively, for 305 , 311,325 , and $368 \mathrm{~nm}$ as averaged over all 23 sites. The net reduction in $R D$ due to change from TRT to L\&A is about 2.3-2.9\% (see Table 2), again with little spectral dependence.

Figure 7 depicts relative mean $R M$ and deviation $R D$ of the noontime spectral $(305,311,325,368 \mathrm{~nm})$ irradiance biases by TOMS retrievals from UVMRP measurements at 27 sites under total-sky conditions during 2000-2004 summers (May-September). On average over all 27 sites, the TOMS retrieval biases in total-sky irradiances for $305,311,325$, and $368 \mathrm{~nm}$ are, respectively, 16.5, 9.5, 8.5, and 7.8\% (Table 2). As compared with the clear-sky result in Fig. 2a, the relative mean biases $R M$ under total-sky conditions have small increases, by 1.1, 1.6, 0.9, and $0.8 \%$ for the 4 bands on average over 27 sites. Larger increases were shown at sites CO12 (9.5\%) and VT02 (4.8\%), where more frequent clouds may actually block the skies and reduce the direct irradiances measured by the UVMRP instruments. The impact of clouds is more significant on relative bias deviations $R D$, which are increased by 5.5, 5.5, 5.8, and $6.1 \%$ at $305,311,325$, and $368 \mathrm{~nm}$, respectively, on average over 27 sites as compared with the clear-sky result in Fig. $2 \mathrm{~b}$. Such $R D$ increases under total-sky conditions are mainly caused by the dominant role of daily cloud variability on surface UV irradiances (Fioletov et al., 2002; Kazantzidis et al., 2006).

Note that the correlation coefficients between relative mean biases $R M$ and total optical depths TODs across 27 sites under total-sky conditions are $0.62,0.53,0.48$, and 0.53 for $305,311,325$, and $368 \mathrm{~nm}$, respectively. As compared with the clear-sky result, all correlations remain statistically significant at the $99 \%$ confidence level; while the values are increased by 0.09 and 0.04 for 305 and $311 \mathrm{~nm}$ and decreased by 0.12 and 0.22 for 325 and $368 \mathrm{~nm}$. Since cloud water has negligible UV absorption and its direct scattering effect has already been included in the retrieval algorithm, the correlation of the TOM biases with the cloud optical depth is supposed to be small. As such, the correlation of the TOMS biases with TOD is expected to be smaller than that with AOD for all spectral bands under cloudy conditions. The existence of clouds, however, also enhances the atmospheric photon path due to multiple scattering and thus the UV absorption by ozone and aerosols, which tends to be stronger in UVB than UVA (Mayer et al., 1998). This indirect effect may explain the correlation increase in the UVB. In addition, the correlation coefficients of $R M$ between total-sky and clearsky across 27 sites are $0.92,0.89,0.83$, and 0.78 for 305,311 , 325 , and $368 \mathrm{~nm}$, respectively. These values are very large, indicating that the spatial characteristics of the TOMS retrieval biases of surface UV irradiances are systematic, representative of both clear and total-sky conditions. The gradual decrease of the correlations between total-sky and clear-sky biases from 305 to $368 \mathrm{~nm}$ is consistent with the decreasing indirect effect of aerosol absorption due to cloud scattering enhancement.

\section{Summary}

This study evaluates surface noontime spectral UV irradiances during the summer (May-September) of 2000-2004 from TOMS satellite retrievals against the MFRSR ground measurements at 27 UVMRP climatological sites. The TOMS retrievals are re-convoluted to match the spectral bands of the UVMRP measurements at 305, 311, 325, and $368 \mathrm{~nm}$ using the DISORT radiative transfer model. The scaling factor for the re-convolution depends on total column ozone and solar zenith angle. The major results are summarized as follows.

The relative mean biases $R M$ of TOMS spectral irradiances against the MFRSR measurements for 305 and $325 \mathrm{~nm}$ are in good agreement with those against the Brewer measurements of the Canadian network (Fioletov et al., 2002) at two collocated UVMRP sites (ON02, SK02) under clearsky conditions. The differences between the TOMS-MFRSR biases and TOMS-Brewer biases are within the calibration uncertainty of the two instruments. One exception is for $305 \mathrm{~nm}$ at SK02, where the large difference (8\%) between the TOMS-Brewer and TOMS-MFRSR biases may be due to changes in the TOMS retrieval products from version 7 to 8.

Under clear-sky conditions, the TOMS biases against the UVMRP measurements vary substantially across the 27 sites. Such variability is mainly caused by local aerosol loadings and tropospheric abundances of gaseous pollutants such as 
$\mathrm{SO}_{2}, \mathrm{NO}_{2}$, and $\mathrm{O}_{3}$. For the 4 spectral bands at 305, 311, 325, and $368 \mathrm{~nm}$, correlations of $R M$ with AOD across UVMRP sites are strongly positive, with coefficients of $0.53,0.49$, 0.60 , and 0.75 , all statistically significant at the $99 \%$ confidence level. The corresponding temporal correlations at individual sites are also highly positive. Thus, the TOMS biases increase with local aerosol loadings, which explains nearly $50 \%$ of the variances.

The tropospheric gaseous pollutants $\mathrm{SO}_{2}, \mathrm{NO}_{2}$, and $\mathrm{O}_{3}$ are known for their strong absorption in the UV spectrum. Given the lack of data for the tropospheric $\mathrm{O}_{3}$ abundances, $\mathrm{NO}_{2}$ may be used as an indirect measure of the $\mathrm{O}_{3}$ effect on the TOMS spectral biases in the rural areas. The correlations of the TOMS relative mean biases with local $\mathrm{SO}_{2}$ abundances across the 27 sites are $0.58,0.42,0.33$, and 0.30 at 305,311 , 325 , and $368 \mathrm{~nm}$, respectively. The corresponding correlations with local $\mathrm{NO}_{2}$ abundances are $0.42,0.41,0.30$, and 0.34 . They are statistically significant at the confidence level of $99 \%(95 \%)$ for $\mathrm{SO}_{2}$ at $305(311) \mathrm{nm}$, but of $95 \%$ for $\mathrm{NO}_{2}$ at both 305 and $311 \mathrm{~nm}$. The correlations for the other two bands are not significant. This result provides the first quantitative measure for the spectral dependence of the TOMS biases on local $\mathrm{SO}_{2}$ and $\mathrm{NO}_{2}$ abundances. In addition, the correlation between the $\mathrm{NO}_{2}$ and $\mathrm{SO}_{2}$ abundances across the 27 sites is 0.6 , significant at the $99 \%$ confidence level. This suggests that these two pollutants at the UVMRP sites may result from similar emissions sources.

The TOMS biases vary with wavelengths. The $R M$ at $305 \mathrm{~nm}$ are systematically higher than other three spectral bands at all sites, with the average enhancement factor of $1.9,2.0$, and 2.2 for 311,325 , and $368 \mathrm{~nm}$, respectively. Such bias enhancement may likely result from the spectral dependence of the $\mathrm{SO}_{2}$, which is substantial at $305 \mathrm{~nm}$ but small for other bands. There exists a strong correspondence of the $R M$ differences between 305 and $368 \mathrm{~nm}$ with local $\mathrm{SO}_{2}$ abundances. Their correlation coefficient across the 27 sites is 0.6 , significant at the $99 \%$ confidence level. On the other hand, the correlation with AAOD is not significant (0.23), which may result from weak sensitivity of the OMI AAOD to boundary layer aerosols and other data quality issues. Furthermore, the uncertainty of the scaling factors for the reconvolution due to total column ozone errors may partially contribute to the above contrast.

The use of a more restrictive local-specific cloud screening method (L\&R) causes a net reduction in relative mean biases by $3.4-3.9 \%$ on average over all sites as compared with the conventional method (TRT). This suggests that the TOMS biases due to cloud contamination within a TOMS grid may account for approximately $25 \%$ for $305 \mathrm{~nm}$ and $50 \%$ for other bands of the total bias. Averaged over all 27 sites, the TOMS retrieval biases in total-sky irradiances for 305, 311, 325, and $368 \mathrm{~nm}$ are $16.5,9.5,8.5$, and $7.8 \%$, respectively. They are enhanced by $1.1,1.6,0.9$, and $0.8 \%$ as compared with the clear-sky values. The small increase of the correlation between the total-sky $R M$ and total optical depth in UVB as compared with the clear-sky result shows the effect of cloud enhancement for the UV absorption. The correlation coefficients between total-sky and clear-sky $R M$ across 27 sites are $0.92,0.89,0.83$, and 0.78 for $305,311,325$, and $368 \mathrm{~nm}$, respectively. The result indicates that the spatial characteristics of the TOMS retrieval biases are systematic, representative of both clear and total sky conditions.

The above results may be limited by the availability and quality of the data. In particular, as comprehensively reviewed by Li et al. (2009), the global mean AOD over ocean from several prominent aerosol products differ substantially, with the overall range of discrepancy amounting to about $50 \%$ of the mean AOD. The AOD values retrieved at the UVMRP sites over land is expected to have much larger uncertainties. We have used AOD instead of AAOD to diagnose the dependence of the TOMS biases on UV radiative absorption of aerosols, mainly because of the difficulty in obtaining direct in situ measurements and the uncertainty in satellite retrievals of AAOD. Most recently, AAOD has been retrieved from the MFRSR measurements at some sites as combined with observations by other instruments (Goering et al., 2005; Krotkov et al., 2005b; Corr et al., 2009). Using new retrievals is necessary to revisit the spectral dependence of the TOMS biases on absorbing aerosol loadings.

Nonetheless, our comparison indicates that ground-based in situ measurements, like those from the UVMRP network, are indispensible in monitoring the atmospheric states and never replaceable by space-based remote sensing retrievals. Given recent satellite retrievals of AAOD and air pollution data with better accuracy after intensive cross-validation against ground-based measurements, our findings can be applied along with the post-calibration method of Krotkov et al. (2005b) to improve the satellite UV retrieval algorithm for the latest OMI as it is a heritage and extension of that for TOMS. In this regard, a future study will focus on the evaluation of the OMI spectral irradiance retrievals against the UVMRP measurement once the Level-3 (global gridded) satellite data become available.

Acknowledgements. The authors thank the TOMS team for the UV product and the TEMIS team for the $\mathrm{SO}_{2}$ and $\mathrm{NO}_{2}$ data. We are grateful to two anonymous reviewers and the ACP editor for instructive suggestions that help a more concise presentation. We also thank Dr. Torres for providing the OMI Level-3 aerosol product. This research was supported by the United States Department of Agriculture UV-B Monitoring and Research Program (UVMRP) grant to the University of Illinois at Urbana-Champaign (AG CSU G-1459-1). We thank Drs. John Davis, Becky Olson, Gwen Scott, and George Janson from UVMRP for providing the ground UV in situ measurements and valuable discussions. The data processing was mainly conducted at the NCSA/UIUC supercomputing facility. The views expressed are those of the authors and do not necessarily reflect those of the sponsoring agencies or the Illinois State Water Survey.

Edited by: B. Mayer 


\section{References}

Amiridis, V., Balis, D., Kazadzis, S., Bais, A., Giannakaki, E., Papayannis, A., and Zerefos, C.: Four-year aerosol observations with a Raman lidar at Thessaloniki, Greece in the framework of EARLINET, J. Geophys. Res., 110, D21203, doi:10.1029/2005JD006190, 2005.

Antón, M., Cachorro, V. E., Vilaplana, J. M., Krotkov, N. A., Serrano, A., Toledano, C., de la Morena, B., and Herman, J. R.: Total ozone mapping spectrometer retrievals of noon erythemalCIE ultraviolet irradiance compared with Brewer ground-based measurements at El Arenosillo (southwestern Spain), J. Geophys. Res., 112, D11206, doi:10.1029/2006JD007254, 2007.

Antón, M., Cachorro, V. E., Vilaplana, J. M., Toledano, C., Krotkov, N. A., Arola, A., Serrano, A., and de la Morena, B.: Comparison of UV irradiances from Aura/Ozone Monitoring Instrument (OMI) with Brewer measurements at El Arenosillo (Spain) - Part 1: Analysis of parameter influence, Atmos. Chem. Phys., 10, 5979-5989, doi:10.5194/acp-10-5979-2010, 2010.

Arola, A., Kazadzis, S., Krotkov, N., Bais, A., Gröbner, J., and Herman, J.R.: Assessment of TOMS UV bias due to absorbing aerosols, J. Geophys. Res., 110, D23211, doi:10.1029/2005JD005913, 2005.

Augustine, J., Hodges, G., Dutton, E., Michalsky, J., and Cornwall, C.: An aerosol optical depth climatology for NOAA's national surface radiation budget network (SURFRAD), J. Geophys. Res., 113, D11204, doi:10.1029/2007JD009504, 2008.

Bais, A.F., Lubin, D., Arola, A., Bernarhd, G., Blumthaler, M., Chubarova, N., Erlick, C., Gies, H.P., Krotkov, N., Lantz, K., Mayer, B., McKenzie, R.L., Piacentini, R., Seckmeyer, G., Slusser, J.R., Zerefos, C., Fioletov, V., Groebner, J., Kyro, E., Slaper H.: World Meteorological Organization, Global Ozone Research and Monitoring Project - Scientific Assessment of Ozone Depletion, Chapter 7: Surface Ultraviolet Radiation: Past, Present and Future, 2007.

Balis, D.S., Amiridis, V., Zerefos, C., Kazantzidis, A., Kazadzis, S., Bais, A. F., Meleti, C., Gerasopoulos, E., Papayannis, A., Matthias, V., Dier, H., and Andreae, M. O.: Study of the effect of different type of aerosols on UV-B radiation from measurements during EARLINET, Atmos. Chem. Phys., 4, 307-321, doi:10.5194/acp-4-307-2004, 2004.

Bigelow, D. S., Slusser, J. R., Beaubien, A. F., and Gibson, J. H.: The USDA Ultraviolet Radiation Monitoring Program, Bull. Am. Meteorol. Soc., 79(4), 601-615, 1998.

Boersma, K. F., Eskes, H. J., and Brinksma, E. J.: Error Analysis for Tropospheric $\mathrm{NO}_{2}$ Retrieval from Space, J. Geophys. Res., 109, D04311, doi:10.1029/2003JD003962, 2004.

Brühl, C. and Crutzen, P. J.: On the disproportionate role of tropospheric ozone as a filter against solar UVB radiation, Geophys. Res. Lett., 16(7), 703-706, 1989.

Buchard, V., Brogniez, C., Auriol, F., Bonnel, B., Lenoble, J., Tanskanen, A., Bojkov, B., and Veefkind, P.: Comparison of OMI ozone and UV irradiance data with ground-based measurements at two French sites, Atmos. Chem. Phys., 8, 4517-4528, doi:10.5194/acp-8-4517-2008, 2008.

Bugliaro, L., Mayer, B., Meerkötter, R., and Verdebout, J.: Potential and limitations of space-based methods for the retrieval of surface UV-B daily doses: A numerical study, J. Geophys. Res., 111, D23207, doi:10.1029/2005JD006534, 2006.

Caldwell, M. M., Bornman, J. F., Ballaré,, C. L., Flint, S. D., and
Kulandaivelu, G.: Terrestrial ecosystems, increased solar ultraviolet radiation, and interactions with other climate change factors, Chapter 3 in Environmental Effects of Ozone Depletion and Its Interactions with Climate Change: 2006 Assessment, United Nations Environment Programme, 65-94, 2006.

Corr, C. A., Krotkov, N., Madronich, S., Slusser, J. R., Holben, B., Gao, W., Flynn, J., Lefer, B., and Kreidenweis, S. M.: Retrieval of aerosol single scattering albedo at ultraviolet wavelengths at the T1 site during MILAGRO, Atmos. Chem. Phys., 9, 58135827, doi:10.5194/acp-9-5813-2009, 2009.

Dave, J. V.: Multiple scattering in a non-homogeneous, Rayleigh atmosphere, J. Atmos. Sci., 22, 273-279, 1965.

DeLuisi, J., Theisen, D., Augustine, J., Disterhoft, P., Lantz, K., Weatherhead, E., Hodges, G., Cornwall, C., Petropavlovskikh, I., Stevermer, A., Wellman, D., and Barnett, J.: On the correspondence between surface UV observations and TOMS determinations of surface UV: A potential method for quality evaluating world surface UV observations, Ann. Geophys., 46, 295-308, doi:10.5194/angeo-46-295-2003, 2003.

Denman, K. L., Brasseur, G., Chidthaisong, A., Ciais, P., Cox, P. M., Dickinson, R. E., Hauglustaine, D., Heinze, C., Holland, E., Jacob, D., Lohmann, U., Ramachandran, S., Dias, P. L. da Silva, Wofsy, S. C., and Zhang, X.: Couplings between changes in the climate system and biogeochemistry. Chapter 7 in Climate Change 2007: the physical science basis. Contribution of Working Group I to the Fourth Assessment Report of the Intergovernmental Panel on Climate Change, edited by: Solomon, S., Qin, D., Manning, M., Chen, Z., Marquis, M., Averyt, K. B., Tignor, M., and Miller, H. L., Cambridge University Press, Cambridge, United Kingdom and New York, NY, USA, 499-588, 2007.

Eck, T. F., Bhartia, P. K., and Kerr, J. B.: Satellite estimation of spectral UVB irradiance using TOMS derived total ozone and UV reflectivity, Geophys. Res. Lett., 22, 611-614, 1995.

Fioletov, V. E., Kimlin, M. G., Krotkov, N., McArthur, L. J. B., Kerr, J. B., Wardle, D. I., Herman, J. R., Meltzer, R., Mathews, T. W., and Kaurola, J.: UV index climatology over the United States and Canada from ground-based and satellite estimates, J. Geophys. Res., 109, D22308, doi:10.1029/2004JD004820, 2004.

Fioletov, V. E., Kerr, J. B., Wardle, D. I., Krotkov, N., and Herman, J. R.: Comparison of Brewer ultraviolet irradiance measurements with total ozone mapping spectrometer satellite retrievals, Opt. Eng., 41, 3051-3061, 2002.

Goering, C. D., L'Ecuyer, T. S., Stephens, G. L., Slusser, J. R., Scott, G., Davis, J., Barnard, J. C., and Madronich, S.: Simultaneous retrievals of column ozone and aerosol optical properties from direct and diffuse solar irradiance measurements, J. Geophys. Res., 110, D05204, doi:10.1029/2004JD005330, 2005.

Papayannis, A., Balis, D., Amiridis, V., Chourdakis, G., Tsaknakis, G., Zerefos, C., Castanho, A. D. A., Nickovic, S., Kazadzis, S., and Grabowski, J.: Measurements of Saharan dust aerosols over the Eastern Mediterranean using elastic backscatter-Raman lidar, spectrophotometric and satellite observations in the frame of the EARLINET project, Atmos. Chem. Phys., 5, 2065-2079, doi:10.5194/acp-5-2065-2005, 2005.

Harrison, L. and Michalsky, J.: Objective algorithms for the retrieval of optical depths from ground-based measurements, Appl. Opt., 33, 5126-5137, 1994.

Herman, J., Krotkov, N., Celarier, E., Larko, D., and Labow, G.: Distribution of UV radiation at the Earth's surface from 
TOMS-measured UV-backscattered radiances, J. Geophys. Res., 104(D10), 12059-12076, 1999.

Herman, J. R. and Celarier, E. A.: Earth surface reflectivity climatology at 340-380 nm from TOMS data, J. Geophys. Res., 102(D23), 28003-28011, 1997.

Herman, J., Bhartia, P., Ziemke, J., Ahmad, Z., and Larko, D.: UVB increases (1979-1992) from decreases in total ozone, Geophys. Res. Lett., 23, 2117-2120, 1996.

Kazadzis, S., Bais, A., Arola, A., Krotkov, N., Kouremeti, N., and Meleti, C.: Ozone Monitoring Instrument spectral UV irradiance products: comparison with ground based measurements at an urban environment, Atmos. Chem. Phys., 9, 585-594, doi:10.5194/acp-9-585-2009, 2009a.

Kazadzis, S., Bais, A., Balis, D., Kouremeti, N., Zempila, M., Arola, A., Giannakaki, E., Amiridis, V., and Kazantzidis, A.: Spatial and temporal UV irradiance and aerosol variability within the area of an OMI satellite pixel, Atmos. Chem. Phys., 9, 45934601, doi:10.5194/acp-9-4593-2009, 2009b.

Kazantzidis, A., Bais, A., Grobner, J., Herman, J., Kazadzis, S., Krotkov, N., Kyro, E., den Outer, P., Garane, K., Gorts, P., Lakkala, K., Meleti, C., Slaper, H., Tax, R. B., Turunen, T., and Zerefos, C. S.: Comparison of satellite-derived UV irradiances with ground-based measurements at four European stations, J. Geophys. Res., 111, D13207, doi:10.1029/2005JD006672, 2006.

Kazantzidis, A., Balis, D. S., Bais, A. F., Kazadzis, S., Galani, E., Kosmidis, E., and Blumthaler, M.: Comparison of Model Calculations with Spectral UV Measurements during the SUSPEN Campaign: The Effect of Aerosols, J. Atmos. Sci., 58, 15291539, 2001.

Krotkov, N. A., Carn, S. A., Krueger, A. J., Bhartia, P. K., and Yang, K.: Band residual difference algorithm for retrieval of SO2 from the AURA Ozone Monitoring Instrument (OMI), IEEE Trans. Geosci. Remote Sens., AURA special issue, 44(5), 1259-1266, doi:10.1109/TGRS.2005.861932, 2006.

Krotkov, N. A., Bhartia, P. K., Herman, J., Slusser, J., Scott, G., Janson, G., Labow, G., Eck, T., and Holben, B.: Aerosol UV absorption experiment (2002 to 2004), part 1: UV-MFRSR calibration and intercomparison with CIMEL sunphotometers, Opt. Eng., 44 (4), 141004, doi:10.1117/1.1886818, 2005a.

Krotkov, N.A., Bhartia, P. K., Herman, J., Slusser, J., Scott, G., Labow, G., Vasilkov, A. P., Eck, T. F., Dubovik, O., and Holben, B. N.: Aerosol ultraviolet absorption experiment (2002 to 2004), part 2: absorption optical thickness, refractive index, and single scattering albedo, Opt. Eng., SPIE, 44, 041005, doi:10.1117/1.1886819, 2005b.

Krotkov, N. A., Herman, J., Cede, A., and Labow, G.: Partitioning between aerosol and $\mathrm{NO}_{2}$ absorption in the UVA, in: Ultraviolet Ground- and Space-based Measurements, Models, and Effects V, edited by: Bernhard, G., Slusser, J. R., Herman, J. R., and Gao, W., Proceedings of SPIE, 5886, (SPIE, Bellingham, WA, 2005), 588601, 2005c.

Krotkov, N. A., Herman, J., Bhartia, P. K., Seftor, C., Arola, A., Kaurola, J., Kalliskota, S., Taalas, P., and Geogdzhaev, I. V.: Version 2 total ozone mapping spectrometer ultraviolet algorithm: problems and enhancements, Opt. Eng., 41, 3028-3039, 2002.

Krotkov, N. A., Herman, J., Bhartia, P. K., Fioletov, V., and Ahmad, Z.: Satellite estimation of spectral surface UV irradiance 2. Effects of homogeneous clouds and snow, J. Geophys. Res., 106, 11743-11759, 2001.
Krotkov, N. A., Bhartia, P., Herman, J., Fioletov, V., and Kerr, J.: Satellite estimation of spectral surface UV irradiance in the presence of tropospheric aerosols 1. Cloud-free case, J. Geophys. Res., 103(D8), 8779-8793, 1998.

Li, Z., Zhao, X., Kahn, R., Mishchenko, M., Remer, L., Lee, K.-H., Wang, M., Laszlo, I., Nakajima, T., and Maring, H.: Uncertainties in satellite remote sensing of aerosols and impact on monitoring its long-term trend: a review and perspective, Ann. Geophys., 27, 2755-2770, doi:10.5194/angeo-27-2755-2009, 2009.

Long, C. N. and Ackerman, T. P.: Identification of clear skies from pyranometer measurements and calculation of downwelling shortwave cloud effects, J. Geophys. Res., 105, 15609-15626, 2000 .

Martin, R. V.: Satellite remote sensing of surface air quality, Atmos. Environ., 42(34), 7823-7843, doi:10.1016/j.atmosenv.2008.07.018., 2008.

Martin, T. J., Gardiner, B. G., and Seckmeyer, G.: Uncertainties in satellite-derived estimates of surface UV doses, J. Geophys. Res., 105(D22), 27005-27012, 2000.

Mayer, B., Kylling, A., Madronich, S., and Seckmeyer, G.: Enhanced absorption of UV radiation due to multiple scattering in clouds: Experimental evidence and theoretical explanation, J. Geophys. Res., 103(D23), 31241-31254, 1998.

McKenzie, R., Seckmeyer, G., Bais, A., Kerr, J., and Madronich, S.: Satellite retrievals of erythemal UV dose compared with groundbased measurements at northern and southern midlatitudes, J. Geophys. Res., 106(D20), 24051-24062, 2001.

McKinlay, A., and Diffey, B.: A reference action spectrum for ultraviolet induced erythema in human skin, In: Human Exposure to Ultraviolet Radiation: Risks and Regulations, edited by: Passchier, W. R. and Bosnjakovic, B. F. M., Elsevier, Amsterdam, The Netherlands, 83-87, 1987.

Norval, M., Cullen, A. P., de Gruijl, F. R., Longstreth, J., Takizawa, Y., Lucas, R. M., Noonan, F. P., and van der Leun, J. C.: The effects on human health from stratospheric ozone depletion and its interactions with climate change, Chapter 2 in Environmental Effects of Ozone Depletion and Its Interactions with Climate Change: 2006 Assessment, United Nations Environment Programme, 25-64, 2006.

Sabburg, J., Rives, J., Meltzer, R., Taylor, T., Schmalzle, G., Zheng, S., Huang, N., Wilson, A., and Udelhofen, P.: Comparisons of corrected daily integrated erythemal UVR data from the US EPA/UGA network of Brewer spectroradiometers with model and TOMS-inferred data, J. Geophys. Res., 107(D23), 4676, doi:10.1029/2001JD001565, 2002.

Scotto, J., Cotton, G., Urbach, F., Berger, D., and Fears, T.: Biologically effective ultraviolet radiation: Surface measurements in the United States, 1974 to 1985, Science, 239, 762-764, 1988.

Seinfeld, J. H. and Pandis, P. J.: Atmos. Chem. Phys.: From Air Pollution to Climate Change, John Wiley, New York, 1326 pp., 1998.

Slusser, J. R., Krotkov, N., Gao, W., Herman, J. R., Labow, G., and Scott., G.: Comparisons of USDA UV shadow-band irradiance measurements of TOMS satellite and DISORT model retrievals under all sky conditions, In Ultraviolet Ground-and Space-based Measurements, Models, and Effects, Proceeding of SPIE Volume 4482, Published by Society of Photographic Instrumentation Engineers (SPIE), Bellingham, WA, USA, 56-63, 2002.

Stamnes, K., Tsay, S., Wiscombe, W., and Jayaweera, K.: A nu- 
merically stable algorithm for discrete-ordinate-method radiative transfer in multiple scattering and emitting layered media, Appl. Opt., 27, 2502-2509, 1988.

Tanskanen, A., Lindfors, A., Maatta, A., Krotkov, N., Herman, J., Kaurola, J., Koskela, T., Lakkala, K., Fioletov, V., Bernhard, G., McKenzie, R., Kondo, Y., O’Neill, M., Slaper, H., den Outer, P., Bais, A. F., and Tamminen, J.: Validation of daily erythemal doses from Ozone Monitoring Instrument with groundbased UV measurement data, J. Geophys. Res., 112, D24S44, doi:10.1029/2007JD008830, 2007.

Tao, Z., Larson, S. M., Wuebbles, D. J., Williams, A., and Caughey, M.: A summer simulation of biogenic contributions to groundlevel ozone over the continental United States, J. Geophys. Res., 108(D14), 4404, doi:10.1029/2002JD002945, 2003.

TEMIS: Sulphur dioxide monitoring within TEMIS, TEM/SO2/001/, 0.9-rev0., http://www.temis.nl/docs/ TEMIS_SO2_09.doc, 44pp, 2006.

Torres, O., Tanskanen, A., Veihelmann, B., Ahn, C., Braak, R., Bhartia, P. K., Veefkind, P., and Levelt, P.: Aerosols and surface UV products from Ozone Monitoring Instrument observations: An overview, J. Geophys. Res., 112, D24S47, doi:10.1029/2007JD008809, 2007.

Wang, P., Li, Z., Cihlar, J., Wardle, D. I., and Kerr, J.: Validation of an UV inversion algorithm using satellite and surface measurements, J. Geophys. Res., 105(D4), 5037-5048, 2000.
Weihs, P., Blumthaler, M., Rieder, H. E., Kreuter, A., Simic, S., Laube, W., Schmalwieser, A. W., Wagner, J. E., and Tanskanen, A.: Measurements of UV irradiance within the area of one satellite pixel, Atmos. Chem. Phys., 8, 5615-5626, doi:10.5194/acp8-5616-2008, 2008.

Wuttke, S., Verdebout, J., and Seckmeyer, G.: An Improved Algorithm for Satellite-derived UV Radiation, Photochem. Photobiol., 77(1), 52-57, 2003.

Xu, M., Liang, X.-Z., Gao, W., Slusser, J. R., and Kunkel, K. E.: Validation of the TUV module in CWRF using USDA UV-B network observations, in: Remote Sensing and Modeling of Ecosystems for Sustainability III, Proceeding of SPIE Volume 6298, Published by Society of Photographic Instrumentation Engineers (SPIE), Bellingham, WA, USA, 0N-1-0N-8, 2006.

Zerefos, C. S., Kourtidis, K., Melas, D., Balis, D. S., Zanis, P., Katsaros, L., Mantis, H. T., Repapis, C., Isaksen, I., Sundet, J., Herman, J., Bhartia, P. K., and Calpini B.: Photochemical Activity and Solar Ultraviolet Radiation (PAUR) Modulation Factors: An overview of the project, J. Geophys. Res., 107(D18), 8134, doi:10.1029/2000JD000134, 2002.

Zerefos, C. S., Meleti, C., Bais, A. F., Lambros A.: The Recent UVB variability over Southeastern Europe, J. Photochem. Photobiol. B: Biology, 31(1-2), 15-19, 1995. 